\title{
Framing and cooperation in public good games : an experiment with an interior solution ${ }^{1}$
}

\author{
Marc Willinger*, Anthony Ziegelmeyer \\ Bureau d'Economie Théorique et Appliquée, Université Louis Pasteur, 38 boulevard d'Anvers, \\ 67000 Strasbourg, France
}

\begin{abstract}
We show that experimental subjects tend to contribute more to the public good if they perceive the actions of the others as a source of positive externality rather than a source of negative externality. In our experiment partial contribution to the public good is the unique subgame perfect equilibrium for the repeated game.
\end{abstract}

\section{Résumé}

Dans cet article, nous montrons que le degré de coopération de sujets placés dans un mécanisme de contribution volontaire est différent suivant que les choix des sujets induisent des externalités positives (contexte positif) ou des externalités négatives (contexte négatif). Les sujets participant au contexte positif ont un taux de sur-contribution supérieur au taux de sur-contribution des sujets participant au contexte négatif. Notre expérience se caractérise par une stratégie dominante d'investissement partiel dans le bien public.

Keywords: Experimental economics; Public goods

JEL classification: C92; H41

\section{Introduction}

Observed cooperation in public good experiments has not yet received a fully satisfactory explanation. Cooperation in public good experiments contrasts sharply with behaviour observed in oligopoly experiments and common pool resources (CPR) experiments. Although, these experiments have the same strategic environment as public good games, the observed results are, in this case, compatible with the game-theoretic predictions (see Ostrom et al., 1994). One possible reason is that in the public good environment subjects perceive the actions of the others as a source of positive externality, while in the oligopoly or CPR environment they perceive those actions as a source of negative externality. In order to test this hypothesis, we designed an experiment similar to Andreoni (1995) which allows a comparison of the two contexts. In the positive context, any token invested by a member of the group in the public activity, pays off the same amount to each member of the group. In the negative context, any token invested by a member of the group in her private activity generates a loss for the other members of the group. Andreoni (1995) found that the average level of contribution is significantly larger in the positive context compared to the negative context. However, his result could be due to a particular combination of design options. Andreoni chose a corner solution design where the dominant strategy is to contribute nothing to the public good, and a strangers design in which subjects are randomly assigned to one of five groups after each period. When the dominant strategy is to contribute nothing cooperation can be due to decision errors. Moreover, in the negative context the strangers design could have reinforced the feeling of adversity induced by the actions taken by the other subjects. Our experiment is based on

\footnotetext{
${ }^{1}$ We would like to thank Claudia Keser for valuable comments and conversations.

* Corresponding author. Tel. : +33 3884152 09, fax: +33 3886137 66, email : willma@ cournot.u-strasbg.fr.
} 
a public good game for which the dominant strategy is to contribute a positive amount to the public good (see Keser (1996)). We chose a partners design, for which subjects are randomly assigned to a group for the whole duration of the experiment.

Section 2 presents the experimental design, section 3 summarizes the results and section 4 concludes by a short discussion.

\section{Experimental Design}

Each participant was randomly assigned to a group of four people (including himself) for the 15 periods of the experiment. At the beginning of each period, each subject was endowed with 20 tokens, which he was asked to allocate between a private activity and a public activity. The constituent game has a dominant strategy equilibrium where each player contributes 7 tokens to the public activity, which is also the level of contribution predicted by the unique subgame perfect equilibrium of the repeated game. Because we have an interior solution, over-contribution can hardly be explained by decision-errors since the cost of a deviation is the same in both directions.

We studied two treatments : the positive treatment is a standard public good game with an interior solution. We replicated the experiment of Keser (1996) with 15 periods instead of 25. In the positive treatment each token invested in the public good generates a uniform gain for each member of the group. In the negative treatment, each token invested in the private activity generates a loss for the other members of the group. The structure of the game is identical in both treatments. Only the presentation differs.

\subsection{The positive treatment}

In the positive treatment, the individual payoff function of agent $\mathrm{i}$ is given by:

$$
\prod_{\mathrm{i}}\left(\mathrm{x}_{\mathrm{i}}, \sum_{\mathrm{j}=1}^{4} \mathrm{t}_{\mathrm{j}}\right)=41 \mathrm{x}_{\mathrm{i}}-\mathrm{x}_{\mathrm{i}}^{2}+15 \sum_{\mathrm{j}=1}^{4} \mathrm{t}_{\mathrm{j}} .
$$

Each player i maximizes $\Pi_{i}$ with respect to $\left(x_{i}, t_{i}\right)$ and subject to the budget constraint $x_{i}+t_{i}=20$, where $x_{i}$ is the number of tokens invested in the private activity and $t_{i}$ the number of tokens invested in the public activity. The reward of the private activity is $41 \mathrm{x}_{\mathrm{i}}-\mathrm{x}_{\mathrm{i}}^{2}$ while the reward of the public activity is given by $15 \sum_{\mathrm{j}=1}^{4} \mathrm{t}_{\mathrm{j}}$. In the positive treatment, contribution to the public activity generates a positive externality for other subjects. This becomes clear if we rewrite expression (1) as:

$$
\prod_{i}\left(x_{i}, \sum_{j \# i} t_{j}\right)=300+26 x_{i}-x_{i}^{2}+15 \sum_{j \# i} t_{j} .
$$

The unique Nash equilibrium is $\mathrm{x}_{\mathrm{i}}^{*}=13$ and $\mathrm{t}_{\mathrm{i}}^{*}=7$. Moreover the repeated game has a unique subgame-perfect equilibrium where each player contributes seven tokens per period to the public activity. The social optimum requires that each member contributes 20 tokens to the public activity.

\subsection{The negative treatment}

The negative treatment is simply a rewriting of the reward structure, in which investing in the private activity appears as generating a negative externality for the other members of the group. Formally, this is done by taking into account the budget constraint of the other players into player i's payoff function (2): 


$$
\begin{aligned}
& \prod_{\mathrm{i}}\left(\mathrm{x}_{\mathrm{i}}, \sum_{\mathrm{j} \# \mathrm{i}} \mathrm{x}_{\mathrm{j}}\right)=300+26 \mathrm{x}_{\mathrm{i}}-\mathrm{x}_{\mathrm{i}}^{2}+15 \sum_{\mathrm{j} \# \mathrm{i}}\left(20-\mathrm{x}_{\mathrm{j}}\right) \\
& \Leftrightarrow \quad \prod_{\mathrm{i}}\left(\mathrm{x}_{\mathrm{i}}, \sum_{\mathrm{j} \# \mathrm{i}} \mathrm{x}_{\mathrm{j}}\right)=300+26 \mathrm{x}_{\mathrm{i}}-\mathrm{x}_{\mathrm{i}}^{2}+900-15 \sum_{\mathrm{j} \# \mathrm{i}} \mathrm{x}_{\mathrm{j}} .
\end{aligned}
$$

The last term of the RHS of equation (4) shows that tokens invested by the three other players generate a loss for agent i. Of course, the framing has no effect on the game itself. A self-interested player still has a dominant strategy to contribute seven tokens to the public activity. Also, the subgame-perfect equilibrium of the 15-period game and the social optimum are the same than in the positive treatment. Thus, the incentives in both treatments are identical. They only differ by the framing of the context. Except for the necessary changes required by our particular design, the instructions are similar to those of Andreoni.

\subsection{Practical procedures}

The experiment was run on a computer network in Spring 1996. We used the "RatImage" (1995) toolbox in order to compute the experiment. Four sessions were organized, with 3 groups of 4 subjects per session. A total of 6 independent observations per treatment was collected. The subjects were recruited by phone from a pool of 500 students, who were willing to participate in an experiment. Subjects earned $30 \mathrm{FF}$ show-up fee along with their earnings in the experiment. The average earning was $89 \mathrm{FF}$, for sessions which lasted about one hour and a half.

Subjects were randomly assigned to a group of four players, to play a 15-fold repetition of the oneshot game, on a computer terminal, which was physically isolated from other terminals. Communication was not allowed. The subjects were instructed about the rules of the game and the use of the computer program through written instructions (available upon request), which were read aloud. A short questionnaire and two practice rounds followed. Subjects earned points that were converted at the end of the session. The number of points accumulated since the beginning of the experiment was on permanent display and subjects could view the payoff history. At the end of a session each subject was paid privately the total amount he/she had earned during the session.

\section{Results}

Table 1 shows, for each independent player group, the average token contribution to the public activity for the 15 periods and for both treatments. In the positive treatment, the average contribution per subject and per period is 12.39. This corresponds to an average per period overcontribution rate of $41.46 \%^{2}$ per subject. In the negative treatment, the average contribution to the public activity per subject and per period is 8.26. This corresponds to an average per period overcontribution rate of $9.69 \%$ per subject.

Table 1

Average contribution for the independent player groups, positive groups (1+ to 6+) and negative groups (1- to 6-)

\begin{tabular}{c|c|c|c|c|c|c|c|c|c|c|c|c}
\hline Group & $1+$ & $2+$ & $3+$ & $4+$ & $5+$ & $6+$ & $1-$ & $2-$ & $3-$ & $4-$ & $5-$ & $6-$ \\
\hline $\begin{array}{c}\text { Average } \\
\text { contribution }\end{array}$ & 13,17 & 12,63 & 11,53 & 9,78 & 13,20 & 14,02 & 9,10 & 7,80 & 9,40 & 6,98 & 10,00 & 6,27 \\
\hline
\end{tabular}

\footnotetext{
${ }^{2}$ The individual over-contribution rate is defined by $\frac{t_{i}-7}{13}$.
} 
In the positive treatment, the average contribution is above the subgame-perfect equilibrium level of contribution (7) for each group. A $\chi^{2}$ test rejects the null hypothesis that the average levels of contribution are equal to 7 at the $1 \%$ level. This result confirms earlier results that showed that subjects significantly over-contribute to the public activity with respect to the dominant strategy.

In the negative treatment, the average contribution is not always above seven for each group. A $\chi^{2}$ test does not reject the null hypothesis that the average levels of contribution are equal to 7 at the $5 \%$ level. Thus, the negative treatment of the public good game with interior solution agrees with the equilibrium prediction.

Fig. 1 shows the time path of the average contributions to the public activity for both treatments. In each period the average contributions are above the dominant solution of seven tokens in the positive framing in contrast to the average contributions in the negative framing.

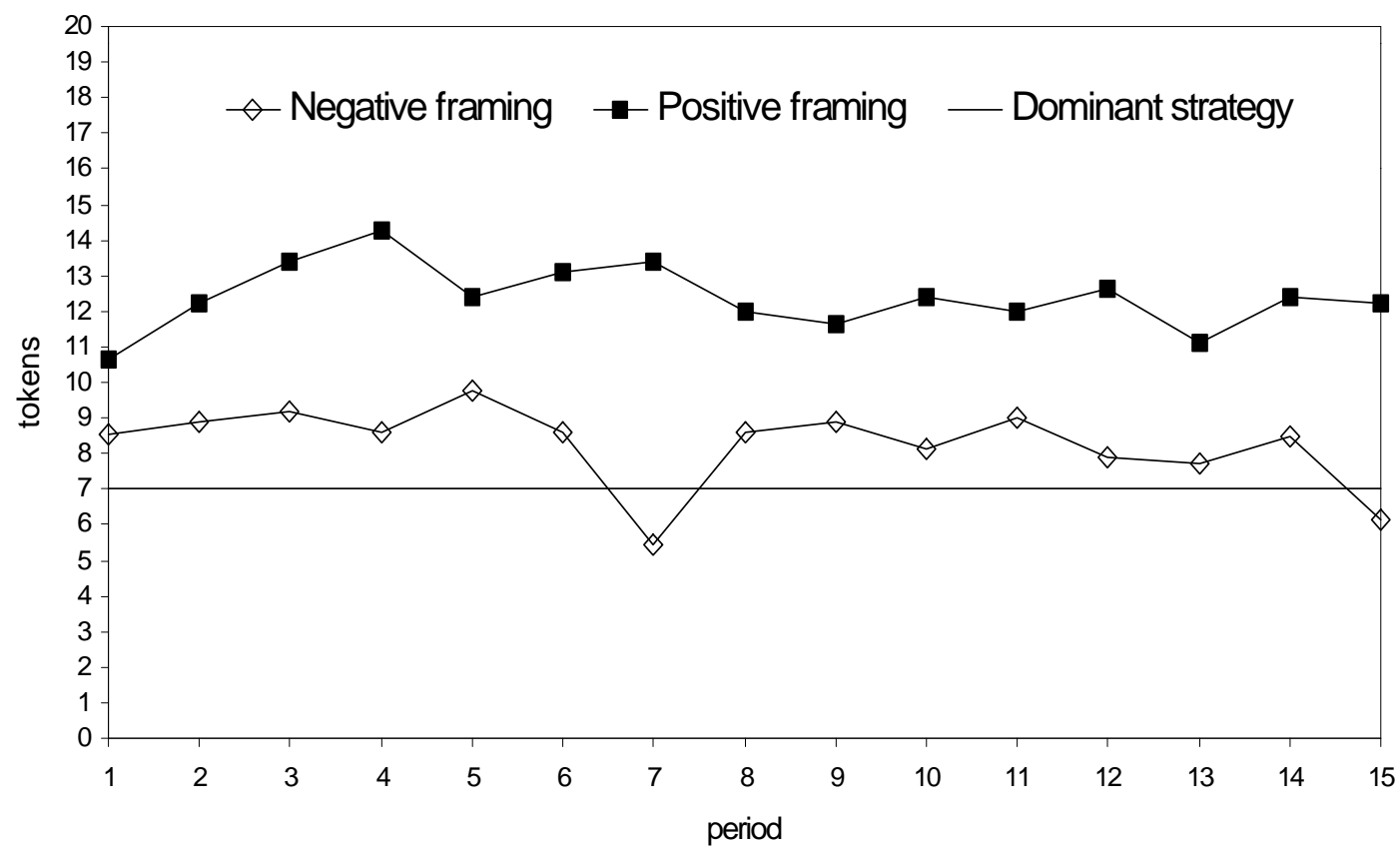

Fig. 1. Time path of the average contributions to the public activity for both treatments.

Applying a two-tailed Mann-Whitney $\mathrm{U}$ test, we can reject the null hypothesis that average contribution levels are the same in both treatments at the $1 \%$ level. We conclude that subjects contribute significantly more in the positive framing than in the negative framing. This result is in line with the observation made by Andreoni (1995). But in contrast to his results, we observe no significant difference in contribution levels in the first period in the two contexts. The gap arises only with the repetition of the one shot game, suggesting that it is not the perception of the environment as such that induces lower contribution in the negative context, but the perception of the others effective contribution.

\section{Discussion and conclusion}

We designed an experiment to test Andreoni's observation that subjects contribute more to the public good when they perceive the actions of the others as a positive externality rather than a negative externality. In contrast to Andreoni, our experimental design is based on an interior solution and on a partners treatment. We observe that the average level of contribution in the negative treatment is significantly lower than in the positive treatment and agrees with the equilibrium prediction. Looking at individual contribution levels, the difference might attributed to 
the fact that more subjects over-contributed in the positive treatment. 80,56 \% of the subjects contributed more than 7 tokens in the positive treatment against 43,33\% only in the negative treatment. The difference is significant at the $1 \%$ level. Moreover, for any integer $\alpha$, such that $1 \leq$ $\alpha \leq 13$, there are more subjects contributing at least $7+\alpha$ tokens to the public good in the positive treatment than in the negative treatment (the difference is always significant at the $1 \%$ level). In the first period the average level of contribution in both treatments is not significantly different. Since the difference becomes significant only with the repetition of the game, it must be the case that, on average, subjects react in the different way to the contribution of the others in the two contexts. However, a better understanding would require a detailed characterization of individual play in both contexts.

\section{References}

Andreoni, J., 1995, Warm-glow versus cold-prickle: the effects of positive and negative framing on cooperation in experiments, The Quarterly Journal of Economics 60, 1-14.

Keser, C., 1996, Voluntary contributions to a public good when partial contribution is a dominant strategy, Economics Letters 50, 359-366.

Ostrom, E., Gardner, R. and J. Walker, 1994, Rules, games, and common-pool resources, University of Michigan Press, Michigan.

RatImage, 1995, Research assistance toolbox for computer-aided human behavior experiments, Klaus Abbink and Abdolkarim Sadrieh, University of Bonn. 